\title{
DO PODER QUE SE IMPÕE E SE AFRONTA
}

\author{
Pedro de Souza $\star$ \\ Universidade Federal de Santa Catarina
}

\begin{abstract}
RÉSUMÉ: La question de cet article est de proposer des éléments pour répondre quelle est la nature des relations impliquant le phénomène du pouvoir chez Michel Foucault. Mon idée est de développer un compte rendu analytique du pouvoir, ce qui signifie non pas d'une définition a-priori, mais de prendre le pouvoir en tant que la réalité des évenements et l'effet d'une manière de penser. Le script pour mon exposition prend comme principe directeur l'idée que le pouvoir, en fait, n'est rien que des relations, y compris les forces de domination et les forces de liberté, des forces imposantes et des forces d'affrontement.
\end{abstract}

MOTS-CLÉS: rélations de force; pouvoir; résistance; discours; subjectivité.

6 m muitas e de diferentes maneiras Foucault abordou o tema do poder, tanto em seus proferimentos escritos quanto nos orais. No entanto, por mais que se vasculhe exaustivamente por todos os seus dizeres, nunca se pode encontrar algo como um conceito preciso de poder. Em verdade, é como se a própria palavra, a cada vez que é pronunciada pelo filósofo, fosse destituída da possibilidade de fazer referência a algo bem determinado. Essa suspensão da palavra com respeito à coisa a que deveria corresponder chega ao paroxismo, quando Michel Foucault profere em 1977 um perturbador enunciado: "Le pouvoir, ça n'existe pas” (O poder, isso não existe).

^pedesou@gmail.com 
Se é sempre de relações que se trata, que natureza de relações envolve o fenômeno do poder? Minha ideia é desenvolver aqui uma consideração, não conceitual, mas analítica do poder, o que significa não partir de uma definição a-priori, mas de tornar visível, como diria o próprio Foucault, a realidade factual do poder como efeito de uma maneira de pensar. Para isso, tomo como roteiro de minha exposição o ponto de vista de Simone Guenoun, que no livro Abécédaire de Michel Foucault se encarregou do verbete "pouvoir". ${ }^{1}$ O ponto de partida da estudiosa é a ideia foucaultiana de que o poder, em verdade, é composto "apenas de relações". ${ }^{2}$ A partir dessa afirmação de base, ou seja, do poder como relação de forças, Guenoun propõe uma pauta de leitura no sentido de evitar o risco de posturas demasiado utilitaristas ou essencialistas com as quais se tende a retomar o tema do poder em Michel Foucault.

$\mathrm{O}$ que a autora quer sugerir é que não se esqueça o valor de ato dos diferentes momentos em que o pensador francês discorre sobre as relações de poder. Guenoun acentua, no pensamento foucaultiano, a determinação de não desvincular o ato de refletir sobre o poder da experiência que o engendra. Sabe-se da obsessão de Foucault em não só se preocupar com as ideias transmitidas mas também pela maneira de as transmitir. Isso sempre vinha mediante uma maneira de dizer que irrompia na fala e na escrita como uma entre muitas outras a se afrontar. Trata-se do dizer a respeito do poder que já traz, no momento em que é formulado, os traços que o mostram agindo e reagindo no interior de um domínio de relações de força. Quando Foucault, muitas vezes, apresentou e definiu o poder pastoral, não fez tanto apresentar um conceito ou uma teoria, mas sim performatizar uma crítica ao que entendia como o modo próprio de dominação da política vigente no contexto mesmo em que realizava sua ação intelectual.

Inclui-se aqui o espanto que causou a imersão de Foucault em reflexões sobre o liberalismo emergente na Europa dos anos de 1970. À época, o filósofo não chegou a propor um gesto de concessão a uma aparente abertura à livre ação individualista, nem tampouco intentou lançar denúncia contra os avatares ideológicos embutido em um âmbito economicista de poder. Fincado sempre na atualidade, tratou apenas de fazer vir à tona os meandros históricos de relações de poder que

${ }^{1}$ Cf. Guenoun, S. Pouvoir. In: .Abécédaire de Michel Foucault. Paris: Vrin, 2004. N. 1, p. 138-141.

${ }^{2}$ Cf. Foucault, M. Le jeu de Michel Foucault. In: . Dits et écrits. Paris: Gallimard, 1994. Vol. III, p. 302. (Todas as traduções do francês são nossas.) 
genealogicamente germinaram o presente posto em questão nos debates eleitorais que precederam o governo D'Estaing. Volto a esse ponto mais adiante. "É preciso - enfatiza Guenoun - escapar tanto à tentação de um estudo genético do poder, encorajado pela publicação de ditos e escrito, quanto a uma leitura clínica (...) à qual a obra se presta facilmente contra a vontade de seu autor". ${ }^{3}$ Vai nessa severa crítica uma referência incidental a reinvestimentos coletivos observados no conceito atual de "biopoder", ou de reflexões individuais e coletivas que retomam a noção de poder fazendo dele ferramenta para interesses outros.

Cabe aqui lembrar os embates de movimentos erigidos em torno da violência contra os homossexuais. Neste quadro, é comum ecoarem discursos cuja crítica consiste em atacar polos de poder como, por exemplo, o da Igreja Católica condenando os atos homossexuais. Contudo se há aí confronto de forças, para Foucault tratar-se-ia não de destrinchar as malhas do poder incidindo contra modos libertários de ser, mas sim de compreender sua lógica, problematizar e colocar em foco suas fronteiras genealógicas. A questão não é como se livrar daquilo que nos interdita em certas relações de poder, mas de compreender como nos tornamos o que somos e como podemos ser outros no mesmo quadro de afrontamento de forças.

Mas o que pode parecer uma crítica ortodoxa e paralisante no ponto de vista de Simone Guenoun vem logo a seguir como um programa de leitura do que, no conjunto da obra de Michel Foucault, diz respeito à temática do poder. Para evitar não cair nas malhas da história das ideias, que Foucault sempre rejeitou, ou na fragmentação descontextualizada, Guenoun propõe três escansões para em cada uma delas localizar o pensamento foucaultiano sobre o poder. Essa abordagem permite descrever tanto atos de ruptura quanto tomadas de posição nos acontecimentos, "fazendo coexistir temporalidades heterogêneas e contraditórias, sobre um fundo contínuo, o clamor surdo, de um corpo inesquecível". ${ }^{4}$

É o caso então de cartografar propriamente não o poder como objeto ou conceito, mas uma analítica em ato segundo os diferentes contextos em que acontece. É o caso ainda de tomar, ao longo da obra, seja escrita ou falada, um pensamento em operação apontando para si enquanto se faz, tanto pelo modo, como pelo que produz no terreno de forças que adentra. Temos assim as três escansões, que, a meu ver,

\footnotetext{
${ }^{3}$ Cf. Guenoun, op. cit, 2004, p. 138
}

${ }^{4}$ Cf. Guenoun, op. cit., p. 138. 
equivaleriam à remissão da palavra "poder" ao estatuto enunciativo ligada aos instantes discursivos em que aparece. Assim se delineia, também a meu ver, a análise que mostra os acontecimentos como unidades rítmicas compondo o ritmo do pensamento sobre o poder sempre imbricado numa temporalidade múltipla e simultânea. Em síntese, tais acontecimentos, em sua diferença e harmonia, podem ser aludidos ao tema da repressão sexual, do poder pastoral, da governamentalidade, do encontro ético do sujeito consigo mesmo, temas cruzados em uma só atualidade de trabalho e de experiência vivida pelo filósofo.

O período após maio de 1968 marca o primeiro recorte em que a analítica do poder emerge como efeito do engajamento de Foucault na cidade. É o momento em que, conforme diria Jean Claude Zancarini, o filósofo sai da biblioteca. ${ }^{5}$ Guenoun extrai daí os engajamentos do pensador na breve experiência de ensino em Vincennes, na militância do Grupo de Informação da Prisão (GIP) e no grupo de reflexão sobre a atualidade e suas possibilidades de atuação. Aqui efetivamente a ênfase sobre o presente desloca a noção de poder dos lugares enunciativos em que é divisão, inclusão/ exclusão tal como na Arqueologia do saber, ou traduz o binômio saber/ poder como em As palavras e as coisas. Abre-se aí um espaço outro em que a analítica aponta para a sociedade de controle, mostrando historicamente o fundamento do poder disciplinar, como se enuncia em Vigiar e punir. Ostenta-se, nesse trabalho do filósofo, uma nova analítica definindo a dimensão institucional e ativa do poder.

Nesta primeira escansão destaca-se pontualmente a resposta à questão muitas vezes repetida por Foucault: afinal em que consiste o poder? Motivado por um ativismo pontual, o filósofo, engajado nas denúncias contra as atrocidades da prisão, responde enquanto age. A resposta instantânea do filosofo dando conta do caráter sui-generis do poder, ou seja, ação atuando sobre si mesma, conduz Guenoun a concluir que "o poder não é nem uma essência, nem uma substância, nem relações de força; ele é primeiramente relacional, relação com outro, entre outros e consigo mesmo". ${ }^{6}$ Certamente são as queixas para as quais o pensador dá voz nos boletins sobre a prisão editados pelo GIP que o levam a concluir que sem liberdade não há poder; a liberdade é o fundamento do poder. Isso não quer dizer que haja confronto entre poder e liberdade.

\footnotetext{
${ }^{5}$ A expressão é de Jean-Claude Zancarini [Sortir de la bibliothèque (Essai cartographie d'un des territoires de Michel Foucault). Texto inédito em francês. Versão italiana publicada em L'Illuminista. Critica e filosofia. Roma, n. 7, anno III, p. 45-79, 2003].

${ }^{6}$ Cf. Guenoun, op. cit., 2004, p. 140.
} 
Foucault torna bem claro sua ideia sobre o próprio das relações de poder: elas encerram um jogo complexo no qual "a liberdade aparece como condição de existência do poder". ${ }^{7}$ A condição de possibilidade do poder assenta-se sim na resistência, mas desde que esta não se abstraia do poder que a subjuga; caso contrário ambos desaparecem, anulando por completo um jogo de relações que só se sustenta enquanto há forças em luta. Por certo foram ainda os prisioneiros que lhe deram a ver que o corpo individual e social é o lugar privilegiado do exercício do poder.

Não importa se a forma que adota o poder advém da pressão direta sobre o corpo ou sobre a fala do indivíduo. Mesmo que se apresente só depois, quando Foucault se recolhe para escrever, fica assim formulada uma analítica do poder proposta em termos de microfísica dos poderes, de modo que não é apenas através da leitura de textos emblemáticos como Vigiar e punir, aparecidos logo em seguida ao seu ativismo no GIP, que nos damos conta de que em Foucault o poder define-se como técnicas políticas sutis incidindo sobre corpos, tratando de torná-los dóceis, de discipliná-los ainda que à revelia deles. A propósito, Jean Claude Zancarini já adverte como o próprio filósofo opera dessa maneira ao explicar o seu interesse pelo poder: Foucault coloca a questão do poder a partir de sua experiência militante, portanto não antes do momento do Grupo de informação sobre as Prisões, nem antes do 'acontecimento' dos anos 68 (acontecimento precisamente no sentido em que o define Foucault: ruptura que transforma os modos de pensar, de agir, de estar juntos, de conceber o mundo). Quando a temática é abordada, ela é precisamente situada na atualidade: "Meu verdadeiro problema é aquele que, aliás, é o problema de todo mundo, o do poder"; (...) Atualmente, nossa atualidade (...) a questão do poder, é bem a questão desse "presente que é nós mesmos".

Penso que se pode aplicar a essa perspectiva o dispositivo de vigilância e captura colocado em ação no longo período de ditadura militar principalmente a exercida no Brasil e na Argentina. No filme Buenos Aires 1977 (Crônica de uma fuga), vê-se a cena em que um anônimo jogador de futebol é capturado e, de olhos vendados, levado para um casarão onde seu corpo recebe toda sorte de agressões cujo único intuito é o de fazê-lo falar.

\footnotetext{
${ }^{7}$ Cf. Foucault, Sujeito e poder. In: Rabinow e Dreyfus. Michel Foucault, uma trajetória filosófica. Rio de Janeiro, Forense Universitária, 1995, p. 244.

${ }^{8}$ Cf. Foucault, op. cit., 2001, p. 400.

${ }^{9}$ Cf. Foucault, op. cit., 2001, p. 266.
} 
Um indivíduo qualquer, mesmo sem nada saber do que se passa, sem nada ter a dizer, é interpelado por um fragmento da microfísica do poder político. Ele tem seu corpo investido em nome de uma ordem disciplinar que, no caso, o intercepta, não por estar onde não deveria estar - esta seria uma das insígnias do controle -, mas por deter a palavra que o denuncia e o conduz, na condição de suspeito, ao espaço da insurreição que coloca em risco o regime militar. A contiguidade entre o corpo da personagem e o de um colega de faculdade que possuía em sua casa um mimeógrafo é o leitmotiv que detona a narrativa do episódio de detenção e tortura de um jovem interposto à margem do embate entre torturadores e guerrilheiros.

Eis aí o quadro de um estado de coisas ao qual Foucault aplicaria uma analítica de poder deslocando as razões do controle disciplinador de sua missão de ordem e segurança para outro que nunca mostra como sendo seu ponto de emergência. Dessa análise, deduz-se por que, de modo pontual, neste estrato da produção intelectual do filósofo, o poder não é redutível às forças que se mostram em sua dinâmica; de um lado e outro das relações de força subjaz uma zona invisível diluindo microavatares de poder. O que anota Philippe Chevallier é elucidativo neste ponto. Afirma o estudioso que, por mais que o poder seja organizado de tal modo a controlar nos mínimos detalhes as ações que se encontram sob seu alvo, há sempre algo que fica fora de seu alcance. Chevallier alude ao fato de que, a despeito de bem se elaborar, é inevitável que o poder "deixe então fora de campo um domínio de relações humanas em que a continuidade é quebrada, a estabilidade, desfeita, a previsibilidade, impossível". ${ }^{10}$

Por isso mesmo, o interesse é abordar não o poder por ele mesmo, enquanto lugar central que a tudo submete e tiraniza, mas como forma multifacetada que investe contra as mais variadas instâncias do corpo social: a escola, a família, os relacionamentos pessoais, as relações de trabalho etc. Em verdade, conforme os termos de um Foucault afetado pelo drama da prisão em seu tempo, o poder não pode ser abordado a não ser em termos de relações de força. A propósito, vale adotar o termo "batalha", proposto por Chevallier ${ }^{11}$ para designar o traço ambíguo, irregular e imprevisível, traço que se pode apreender na dinâmica que toma o poder em suas diferentes formas históricas de genealogia. A batalha é a metáfora que expõe tanto as forças que alimentam o poder quanto aquelas que apontam para o seu limite.

\footnotetext{
${ }^{10}$ Cf. Chevallier, P. Le pouvoir et la bataille. Nantes: Éditions Pleins Feux, 2004, p. 39.

${ }^{11}$ Cf. Chevallier, op. cit., p. 49.
} 
O limite, nos termos de Chevallier, embora ameace e afronte, não faz desaparecer o poder dando lugar ao estado de liberdade absoluta, mas sim o transforma em outra forma de poder. Dito de modo diverso, ainda que o poder possa sub-repticiamente ser vencido pelo que ele acreditava dominar, o que de fato acontece nessa inversão é outra modalidade de relações de força gerando descontinuamente formas outras de poder. Daí pode se deduzir que a passagem de um sistema político mais controlador a outro mais liberal não significa varredura do poder nas relações sociais.

Aqui, seguindo a tríplice escansão proposta por Guenoun, nos encontramos diante de um outro movimento da sinfonia que compõe a abordagem do poder em Michel Foucault. O segundo procedimento de decomposição do pensamento foucaultiano sobre o poder em seus elementos composicionais alinhados ao ritmo da atualidade em que se insere o filósofo francês nos leva ao cenário do liberalismo giscardiano. Nesse estrato histórico, vemos Foucault agir mediante uma analítica em que põe em questão a forma que toma o poder político no governo de Valéry Giscard d'Estaing (1974-1981). A ação pontual consiste em desmascarar no discurso político aí apreendido sua aspiração à soberania jurídico-legal.

Com esse movimento analítico, segundo Guenoun, Foucault focaliza um novo modelo de relações de poder, cujo mote é a "governamentalidade", mas que só será retomado em 1978, primeiro de modo transitório, depois concentrado, quando o estudioso ministra o curso Segurança, Território e Sociedade. A analítica adotada aponta no governo de Giscard d'Estaing uma noção de liberalismo não jurídico e não político, rastreado no quadro da guerra das raças.

No mesmo cenário do embate político sobre a governamentalidade Guenoun propõe examinar as ocasiões em que, nos anos de 1974-76, a remissão ao poder por Foucault desliza entre dois terrenos. Assim é que a terceira escansão sobrepõe-se em cadeia à segunda. $\mathrm{O}$ primeiro deslize, juntando-se à problematização do liberalismo, mostra-se no que ele identificou como "racismo de Estado" envolvendo o nacionalismo, o socialismo, o fascismo e o comunismo. Pontualmente nos cursos $A$ vontade de saber, de 1976, e Em defesa da sociedade, torna-se central a reflexão sobre a guerra e as relações de força. Parece ter havido aí um projeto de investigar as relações de poder que compõem um estado de guerra.

Mas o interesse pela temática bélica termina repentinamente dando brecha ao segundo deslize de terreno, conforme veremos em seguida. Em verdade, a guerra como componente das relações de poder traveste-se de outra feição. O caso é de pensar, nas palavras de Michel 
Foucault, que "a política é a guerra continuada por outros meios". ${ }^{12}$ Toma então o centro do interesse a reflexão sobre a governamentalidade, já em curso no momento em que o filósofo francês desenvolve o curso É preciso defender a sociedade. Em janeiro de 1978, Foucault inicia o curso Segurança, território, população, ainda falando de poder, deslizando, logo após a primeira aula, para o tema da governamentalidade. No deslize que se verifica nesse ponto, é imediato antever a ligação entre a problemática do governo e do cuidado de si, quando a questão do poder vem colocada nos termos de "como ser governado o menos possível", reflexão que se transmuta em uma atuação crítica em direção ao regime da governamentabilidade liberal.

No interior de um mesmo período de trabalho, a perspectiva foucaultiana de poder singulariza-se no aparecimento de uma História da Sexualidade, em 1976. Isso se dá imediatamente antes que o tema da governamentalidade passe a ser focado no âmbito da ética do cuidado de si. Os interesses pela governamentalidade, pelo governo de si, pelo cuidado de si, pela hermenêutica do sujeito, pelo dizer verdadeiro formam o elo de uma cadeia, indicada nas palavras do próprio Michel Foucault:

Enquanto a teoria do poder político, como instituição, refere-se ordinariamente, a uma concepção jurídica do sujeito de direito, pareceme que a análise da governamentalidade - isto é, análise do poder como conjunto de relações reversíveis - deve referir-se a uma ética do sujeito referido na relação de si para consigo. Isso significa muito simplesmente que no tipo de análise que desde há muito tempo busco lhes propor devemos considerar que relações de poder/ governamentalidade/ governo de si e dos outros/relação de si para consigo compõem uma cadeia, uma trama e que é em torno destas noções que se pode, a meu ver, articular a questão da política e a questão da ética. ${ }^{13}$

Nos termos de Guenoun, este é o momento em que a nova forma do cuidado da vida relacionada aos biopoderes é inversamente refletida no espelho no cuidado de si formulado por outra modalidade de hermenêutica do sujeito. Inverte-se inteiramente a perspectiva. Já não importam as relações de poder que assujeitam, não interessa o poder que investe contra o indivíduo conduzindo seu modo de ser sujeito,

\footnotetext{
${ }^{12}$ Cf. Foucault, M. Em defesa da sociedade. Curso do Collège de France -1975-1976. São Paulo: Editora Martins Fontes, 1999, p. 55.

${ }^{13}$ Cf. Foucault, M. A Hermenêutica do sujeito. Trad. de Márcio Alves da Fonseca e Salma Tannus Muchail. São Paulo: Martins Fontes, 2006, p. 307.
} 
mas sim o sujeito mesmo agindo ainda que inexoravelmente sob os auspícios do poder. Houve, no trabalho de Foucault, o tempo em que, ao constatar a injunção a deixar-se interpelar pela ordem do discurso, o problema tornou-se definitivamente o do próprio poder que assujeita.

Em sua última fase de atuação intelectual, trata-se, na noção de Foucault, mais da forma que o sujeito adota ao se perceber, voluntariamente ligado ao poder quando, mesmo em meio ao mais genuíno dispositivo de obediência, há uma lasca de liberdade que subsiste. Foucault destaca, entre as forças do cristianismo que convocava a todo e cada indivíduo a obedecer a um só regime de subjetivação, atitudes de resistência pelas quais os indivíduos tomavam o cristianismo como referência de seu dizer verdadeiro, à revelia da instituição cristã.

Mas isso vale também para as reflexões imediatamente anteriores, como as que se expõem no curso Hermenêutica do Sujeito. Aí o percurso da ascese do estoicismo ao cristianismo promove relações de força tecendo a forma do sujeito que tem a si e só a si como objeto de cuidado, em contraposição à forma do sujeito cristão que se converte ao cuidado de si tendo como alvo a salvação que se encontra em outro, fora de si. Contudo, ainda que perfilando modos heterogêneos de assujeitamento e consequente subjetivação, Foucault reflete sobre essa cultura de si na antiguidade romana tornando visíveis cenas de relação de força em que, ainda que se seja levado a obedecer, o que importa é o que no próprio indivíduo permanece como força deixando-se levar - não obstante que seja o poder mesmo que põe a nu tais forças que no corpo do sujeito são adversas ao seu investimento dominante. Se o poder não existe sem pressupor resistência, esta, por sua vez, quando o suplanta o que lhe faculta é apenas fazer gerar poder.

Chevallier tem razão ao afirmar que, em sendo o outro do poder, seu ponto obscuro, a resistência é a fronteira-limite de aparecimento e desaparecimento do poder. De modo que fazer a história da cultura de si teria sido um outro modo de o autor de As vidas infames mostrar que o poder nada é se não se fizer em face da liberdade. Sobre esse ponto elucida Paul Veyne referindo-se ao pensamento foucaultiano:

Vamos mais longe: o homem não para de inventar, de criar o novo quaisquer que sejam os motivos ou móveis, sociais ou individuais, que o "empurram" (...) ainda é preciso que haja liberdade de se deixar assim empurrar para fazer o novo, em lugar de permanecer prisioneiro de sua embocadura discursiva. ${ }^{14}$

\footnotetext{
${ }^{14}$ Veyne, Foucault, sa pensée, sa personne. Paris, Editions Albin Michel, 2008, p. 145.
} 
Retorno ao meu ponto de partida, ou seja, a entrada da palavra "poder" no Abécédaire de Michel Foucault. O essencial a reter nessa consideração sugerida no verbete de Simone Guenoun é a presença viva de um apaixonado ato de interrogação aplicado às modalidades e aos campos de relações de poder em ato no momento em que Foucault trabalhava no Collège de France. A constante balizando a analítica foucaultiana do poder reside na oposição a paradigmas dominantes no mesmo instante em que posta em funcionamento, quer pelos textos, quer pelas ações que emanam do pensamento ativo de Michel Foucault operando no presente imediato, qual cirurgião no corpo do moribundo.

Assim é que ele fazia surgir o pensar de outro modo, outro possível. Isso, afirma Guenoun, ${ }^{15}$ sem se desligar dos movimentos, das demandas que foram a ocasião desse mesmo pensamento do poder. O que impulsionava o filósofo a pensar as relações de poder a cada conjuntura política e social era ao mesmo tempo o perigo e o corpo como alvo de todo risco. Por isso mesmo, tal como Sócrates em seu momento final, também Foucault, ministrando seu último curso, Coragem da verdade, expôs a própria saúde por um fio para apontar, contra todas as evidências da forma moral do poder presente, a possibilidade de uma vida e de uma verdade outra.

\section{Referências}

FOUCAULT, M. A Hermenêutica do sujeito. Trad. Márcio Alves da Fonseca e Salma Tannus Muchail. São Paulo: Martins Fontes, 2006, p. 307.

. Em defesa da sociedade. Curso do Collège de France-1975-1976. São Paulo: Editora Martins Fontes, 1999

. Dits et écrits. Paris: Gallimard, 2001. Tome II.

. Sujeito e poder. In: Rabinow e Dreyfus. Michel Foucault, uma trajetória filosófica.

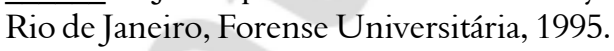
Vol. III. . Le jeu de Michel Foucault. In: Dits et écrits. Paris: Gallimard, 1994.

CHEVALLIER, P. Le pouvoir et la bataille. Nantes: Éditions Pleins Feux, 2004.

GUENOUN, S. Pouvoir. In: 2004.n. 1, p.138-141. . Abécédaire de Michel Foucault. Paris Vrin,

\footnotetext{
${ }^{15}$ Cf. Guenoun, op. cit., p. 140.
} 
VEYNE, P. Foucault, sa pensée, sa personne. Paris: Albin Michel, 2008, p. 145.

ZANCARINI, J.-C. Sortir de la bibliothèque. Essai cartographie d'un des territoires de Michel Foucault (texto inédito em francês. Versão italiana publicada em L'Illuminista. Critica e filosofia. Roma, n. 7, anno III, p. 45-79, 2003). 